Original Article

\title{
Effects of Nintendo Wii Fit Plus training on ankle strength with functional ankle instability
}

\author{
KI-Jong Kim, PT, PhD ${ }^{1)}$, Hyun-Ju Jun, PT, PhD ${ }^{1)}$, Myoung Heo, PT, PhD ${ }^{2 *}$ \\ 1) Department of Physical Therapy, Cheongam College, Republic of Korea \\ 2) Department of Occupational Therapy, Gwangju University: 277 Hyodeok-ro, Nam-gu, Gwangju, \\ Republic of Korea
}

\begin{abstract}
Purpose] The objective of this study was to examine the effects of a training program using the Nintendo Wii Fit Plus on the ankle muscle strengths of subjects with functional ankle instability. [Subjects and Methods] This study was conducted using subjects in their 20 s who had functional ankle instability. They were randomized to a strengthening training group and a balance training group with 10 subjects in each, and they performed an exercise using Nintendo Wii Fit Plus for 20 minutes. In addition, every participant completed preparation and finishing exercises for 5 minutes, respectively. [Results] The muscle strengths after conducting plantar flexion and dorsiflexion significantly increased at the angular velocities of $60^{\circ}$ and $120^{\circ}$ in the strengthening training group. Furthermore, the muscle strengths after conducting plantar flexion, dorsiflexion, eversion, and inversion significantly increased at the angular velocities of $60^{\circ}$ and $120^{\circ}$ in the balance training group. [Conclusion] The balance training group using Nintendo Wii Fit Plus showed better results than the strengthening training group. Consequently, it is recommended to add the balance training program of the Nintendo Wii Fit Plus to conventional exercise programs to improve ankle muscle strength in functional ankle instability at a low cost. Key words: Nintendo Wii Fit Plus, Functional ankle instability, Strength
\end{abstract}

(This article was submitted Jun. 19, 2015, and was accepted Aug 5, 215.)

\section{INTRODUCTION}

Ankle sprain is the most frequent musculoskeletal disorder, which affects activities of daily living ${ }^{1)}$. Furthermore, it can be accompanied by a fracture and eventually has adverse effects on activities of daily living ${ }^{2}$. According to Bendahou et al. ${ }^{3)}$, ankle sprain is very frequent among emergency room patients and generates considerable treatment costs. Functional ankle instability (FAI) refers to the subjection state in which the subject feels giving way as a result of repetitive ankle sprains ${ }^{4}$.

The causes of FAI include lack of muscle force and lack of a sense of balance ${ }^{5)}$. In a previous study on the relationship between ankle instability and strength, Abdel-aziem and $\mathrm{Draz}^{6)}$ reported the muscle torque ratio of dorsiflexion and plantar flexion in chronic ankle instability increased compared to the control group, whereas the muscles torque ratio of inversion and eversion decreased compared to the control group. Furthermore, the eccentric muscle force was significantly lower in plantar flexion, inversion, and eversion. Therefore, the recovery of normal ankle strength is a precondition for the prevention and treatment of repetitive

*Corresponding author. Myoung Heo (E-mail: hmdong2@ hanmail.net)

(C2015 The Society of Physical Therapy Science. Published by IPEC Inc. This is an open-access article distributed under the terms of the Creative Commons Attribution Non-Commercial No Derivatives (by-ncnd) License $<$ http://creativecommons.org/licenses/by-nc-nd/3.0/>. ankle sprains.

Exergames, which refer to video games that include elements for exercise, have been developed recently, enabling subjects to participate actively in the games, unlike conventional games in a sitting position ${ }^{7-9)}$. As exergames are gaining greater popularity among youth, they have become very influential in health, education, and sports ${ }^{10,11)}$.

One of the most widely used video game these days is Nintendo Wii ${ }^{\mathrm{TM}}{ }^{12}$. Nintendo Wii offers a wide variety of games, and Wii Fit Plus is one of them. Wii Fit Plus is being used in various applications, including clinical applications for subjects who need motor learning and feedback training ${ }^{13-15)}$. Therefore, in this study, the effects of a training program in Nintendo Wii Fit Plus on the ankle muscle strength of subjects with FAI were examined.

\section{SUBJECTS AND METHODS}

\section{Subjects}

This study was conducted with subjects in their 20s (age $=23.3 \pm 2.4$ years) who had FAI (gender $=4$ male and 16 female; height $=163.1 \pm 7.4 \mathrm{~cm}$; weight $=55 \pm 10.2 \mathrm{~kg}$ ). The subjects were selected among those who had experienced an ankle sprain in the past, who had no records of operations of their ankles, and who had not participated in other rehabilitation programs. FAI was measured with the Cumberland ankle instability tool (CAIT) and 20 subjects with a score of 24 or lower were selected (CAIT $=18.3 \pm 5.4$ score). They were randomized to the strengthening training group and the balance training group with 10 subjects in each, and they 
performed an exercise using the Nintendo Wii Fit Plus for 20 minutes. Furthermore, every participant completed preparation and finishing exercises for 5 minutes, respectively. The intensity of exercise was adjusted to the needs of the subjects under the supervision of a physiotherapist.

This study was reviewed and received approval from the Gwangju Oriental Hospital of Dongshin University beforehand (IRB No. DSGOH-019). The purpose and intent of this study were explained to every participant who consented to voluntary participation.

\section{Methods}

The Nintendo Wii Fit Plus contains programs that aim to enhance muscle strength as well as those that aim to enhance the sense of balance. For muscle strengthening exercise, lunges, single leg extensions, sideways leg lifts, single leg twists, and rowing squats were performed. In the lunges, a player began with a posture of lacing their fingers behind his/her heads and had $90^{\circ}$ flexion between the hip and knee joints of the former leg, while keeping the torso straight. The rear foot was placed about two steps behind the former foot, and the players had $90^{\circ}$ flexion knee with the hip joint in slight flexion. The more weight players put on the ankle, the higher the red gauge moved; the gauge had to reach at least above the blue line. In the single leg extensions, players kept a flexion condition of a single hip and knee joint while standing on the opposite leg. When moving the bent leg in anterior-posterior ways, players naturally moved their arms in the anterior-posterior direction while maintaining $90^{\circ}$ flexion in the opposite side's elbow and shoulder joints. In order to maintain the body's balance, the center of the body needed to not deviate from the yellow part. In order to reinforce the ankle, the players concentrated on the ankle when applying weight. In the sideways leg lifts, the players began with a posture of standing on one foot and had an abduction of the arm and the opposite side's leg as much as possible while maintaining the center of the body within the boundary of the yellow part. To enhance muscle strength, the players concentrated on their ankles. In the single leg twists, the players stood on one foot and maintained a posture of bending the opposite hip and knee joints. At the same time, they lowered their arms in a diagonal direction and twisted the body such that the back of the hand touched the knee. In the rowing squats, the players repeated flexion and extension of both legs concurrently with repetition of flexion and extension of both arms. The players flexed their elbow joints as if gathering axilla in the center, while extending the shoulder joint. The center of the body had to stay within the interior of the blue part, and the knee had to avoid advancing before the toe.

For exercise that enhances balancing sense, participants headed soccer balls, tightrope walked, table tilted, and slalomed on both snowboards and skis. In the soccer heading activity, the players headed soccer balls by moving the center of the body left-right; they could get higher scores in case of continuous headers. The players had to avoid any objects other than soccer balls, and they were able to think ahead, as the number of soccer balls remaining was displayed on the upper-left part of the screen. In the ski slalom, the players passed flag marks in sequence by mov-

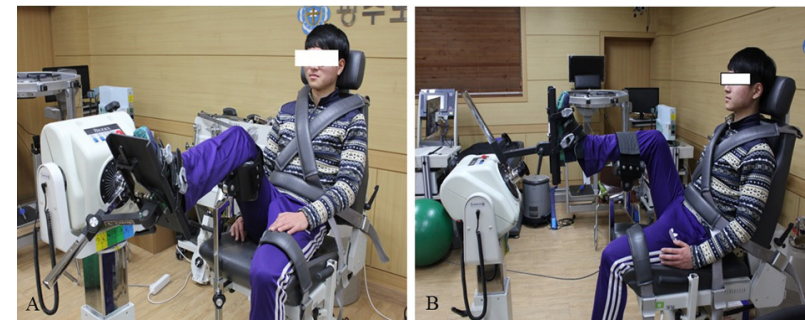

Fig. 1. Measure of ankle strength

(A) Plantar-dorsi flexion. (B) Inversion-eversion

ing left-right and anterior-posterior. The number of missed flags, elapsed time, and current speed were all displayed on the screen. Moreover, the players could see how their center of gravity was moving at the current time by looking at the screen. Time was measured upon reaching the arrival point, and their final times were calculated by adding the timeconverted number of missed flags. In the tightrope walk, the players controlled the characters such that they did not fall from the single stripe. When the body was tilted toward one side, the player had to immediately balance toward the opposite side in order not to fall; they had to do this as quickly as possible, since there was a time limit. Obstacles appeared frequently in order to interrupt their progress, and their characters had to jump adeptly to avoid them, after which balancing is important in the landing process. In the table tilt, the players had to put a bead in holes by moving their bodies left-right and anterior-posterior; the number of beads or difficulty level increased in the higher stages. Moreover, the exercise required concentration, since there was a time limit. The players could proceed to the next level once they cleared one stage. The snowboard slalom began after standing the Wii Balance Board vertically, as if actually snowboarding; the players could maintain their body balance by moving forward and backward while standing sideways on the board. The players had to pass the flag marks in regular sequence in order to obtain a high score; their final score was computed by adding up the times they took to pass the flag marks, similar to the ski slalom.

The Biodex isokinetic dynamometer (Biodex Medical Systems, Shirley, NY, USA) was used to measure the muscle strength of the ankle. For the measurement of plantar flexion and dorsiflexion, the subject started from $40^{\circ}$ plantar flexion, moved on to $20^{\circ}$ dorsiflexion, and then returned to plantar flexion in one cycle, and five cycles were measured for each patient. For inversion and eversion, the subject started from $30^{\circ}$ inversion, moved on to $20^{\circ}$ eversion, and then returned to inversion as one cycle, and five cycles were measured for each patient. The angular velocity was set to $60^{\circ}$ and $120^{\circ}$, and a one-minute recess was given between different angular velocities $^{16)}$ (Fig 1).

The descriptive statistics of all the measurement data, including average and standard deviation, were calculated using the statistics application PASW version 18.0. The normal distribution was examined through the One Sample Kolmogorov-Smirnov test, and the significant differences of the results before and after the exercise were analyzed 
Table 1. Effects of the Nintendo Wii Fit Plus training on the ankle muscle strength (Nm)

\begin{tabular}{lccccc}
\hline & \multirow{2}{*}{$\begin{array}{c}\text { Angular } \\
\text { velocity }\end{array}$} & \multicolumn{2}{c}{ Strengthening group } & \multicolumn{2}{c}{ Balance group } \\
\cline { 2 - 5 } & $60^{\circ}$ & $30.9 \pm 12.6$ & $51.5 \pm 13.5^{*}$ & $33.1 \pm 21.2$ & $72.7 \pm 35.7^{*}$ \\
\hline Plantar & $120^{\circ}$ & $22.3 \pm 7.9$ & $42.0 \pm 9.3^{*}$ & $26.6 \pm 18.9$ & $60.6 \pm 37.8^{*}$ \\
flexion & $60^{\circ}$ & $15.7 \pm 6.2$ & $26.1 \pm 4.1^{*}$ & $15.7 \pm 5.0$ & $24.2 \pm 10.0^{*}$ \\
Dorsi & $120^{\circ}$ & $12.9 \pm 5.9$ & $21.4 \pm 6.9^{*}$ & $12.7 \pm 7.2$ & $22.7 \pm 13.7^{*}$ \\
flexion & $60^{\circ}$ & $19.5 \pm 6.4$ & $21.6 \pm 10.7$ & $11.7 \pm 6.6$ & $22.2 \pm 9.3^{*}$ \\
& $120^{\circ}$ & $18.7 \pm 4.5$ & $20.2 \pm 7.9$ & $10.3 \pm 5.8$ & $20.4 \pm 10.1^{*}$ \\
Eversion & $60^{\circ}$ & $23.6 \pm 13.2$ & $23.7 \pm 15.4$ & $14.8 \pm 6.0$ & $21.2 \pm 7.5^{*}$ \\
& $120^{\circ}$ & $21.3 \pm 10.7$ & $19.2 \pm 10.5$ & $12.4 \pm 6.2$ & $20.2 \pm 8.3^{*}$ \\
\hline
\end{tabular}

Mean \pm SD, $* \mathrm{p}<0.05$

through the paired sample t-test. The statistical significance level $\alpha$ was set to 0.05 .

\section{RESULTS}

The strengthening training group showed a significant increase in the muscle strength of plantar flexion at the angular velocities of $60^{\circ}(\mathrm{t}=-2.710, \mathrm{p}=0.024)$ and $120^{\circ}(\mathrm{t}$ $=-4.889, \mathrm{p}=0.001)$ after the exercise. Furthermore, the balance training group also showed a significant increase in the muscle strength of plantar flexion at the angular velocities of $60^{\circ}(\mathrm{t}=-5.060, \mathrm{p}=0.001)$ and $120^{\circ}(\mathrm{t}=-4.209, \mathrm{p}=0.002)$ after the exercise (Table 1).

The strengthening training group showed a significant increase in the muscle strength of dorsiflexion at the angular velocities of $60^{\circ}(t=-6.892, p=0.000)$ and $120^{\circ}(t=-6.594$, $\mathrm{p}=0.000)$ after the exercise. Furthermore, the balance training group also showed a significant increase in the muscle strength of dorsiflexion at the angular velocities of $60^{\circ}(\mathrm{t}=$ $-2.736, \mathrm{p}=0.023)$ and $120^{\circ}(\mathrm{t}=-2.863, \mathrm{p}=0.019)$ after the exercise (Table 1).

The strengthening training group showed no significant differences in the muscle strength of eversion at the angular velocities of $60^{\circ}(\mathrm{t}=-1.193, \mathrm{p}=0.263)$ and $120^{\circ}(\mathrm{t}=$ $-0.758, p=0.468)$. On the other hand, the balance training group showed a significant increase in the muscle strength of eversion at the angular velocities of $60^{\circ}(\mathrm{t}=-8.459, \mathrm{p}=$ $0.000)$ and $120^{\circ}(\mathrm{t}=-5.303, \mathrm{p}=0.000)($ Table 1$)$.

The strengthening training group showed no significant differences in the muscle strength of inversion at the angular velocities of $60^{\circ}(\mathrm{t}=-0.040, \mathrm{p}=0.969)$ and $120^{\circ}(\mathrm{t}=1.140$, $\mathrm{p}=0.284)$. On the other hand, the balance training group showed a significant increase in the muscle strength of inversion at the angular velocities of $60^{\circ}(\mathrm{t}=4.659, \mathrm{p}=0.001)$ and $120^{\circ}(\mathrm{t}=-4.776, \mathrm{p}=0.001)($ Table 1$)$.

\section{DISCUSSION}

As a result of the training with Nintendo Wii Fit Plus, the strengthening training group showed a significant increase in the muscle strength of plantar flexion at the angular velocities of $60^{\circ}$ and $120^{\circ}$ after the exercise. This result was the same as the result of the muscle strengthening exercise using Therabands for subjects with functional ankle instability in their 20s, which increased plantar flexion ${ }^{5)}$. Thus, this study found the muscle strength of plantar flexion could be increased through Nintendo Wii Fit Plus training as well. The balance training group showed a significant increase in the muscle strength of plantar flexion at the angular velocities of $60^{\circ}$ and $120^{\circ}$ after the exercise. It seems the repetition of back and forth movements in the balance exercises, such as Ski Slalom, Snowboard Slalom, and Table Tilt, increased plantar flexion. This is also supported by previous studies that found the Ski Slalom exercise allowed the repetitive learning of posture adjustment ${ }^{17-19)}$. According to the gait analysis to determine the importance of the exercise for plantar flexion, the delay of the maximum plantar flexion is associated with ankle sprain. Therefore, continuous consideration of plantar flexion is required for the effective rehabilitation of the ankle sprain ${ }^{20}$.

The strengthening training group showed a significant increase in the muscle strength of dorsiflexion at the angular velocities of $60^{\circ}$ and $120^{\circ}$ after the exercise. The weakening of the muscle strength of dorsiflexion directly affects balance and gait, and the weakening of the ankle muscle strength is the most common neuromuscular disorder ${ }^{21,22)}$. Therefore, it is very meaningful that the muscle strength of dorsiflexion significantly increased in this study from the Nintendo Wii Fit Plus training. The balance training group showed a significant increase in the muscle strength of dorsiflexion at the angular velocities of $60^{\circ}$ and $120^{\circ}$ after the exercise. This indicates the balance exercise of this study can help strengthen the muscle strength of dorsiflexion. The weakening of dorsiflexion is a critical element of recurring ankle sprain $^{23,24)}$. According to Crosbie et al. ${ }^{25)}$, the weakening of dorsiflexion slows down the walking speed and shortens the step length and single support time, resulting in asymmetry. Furthermore, it is particularly important as a predictor of the possibility of gait $^{26)}$. Considering these facts, the strengthening training of dorsiflexion is very important.

The balance training group showed a significant increase in the muscle strength of eversion at the angular velocities of $60^{\circ}$ and $120^{\circ}$ after the exercise. This seems to be due to the fact that the balance exercises of this study, i.e., Soccer Heading, Ski Slalom, Tight Rope Walk, Table Tilt, and Snowboard Slalom, have many motions in the medial-lateral direction. Son et al. ${ }^{27)}$ insisted the ankle muscle strength exercise had a positive correlation with balance, and this seems 
to be the reason the balance training in this study improved muscle strength. However, the strengthening training group showed no significant difference in the muscle strength of eversion at the angular velocities of $60^{\circ}$ and $120^{\circ}$. The reason for this result seems to be that even though Nintendo Wii Fit Plus can be used as a therapeutic tool for functional improvement, it was originally designed for entertainment ${ }^{28)}$. Among the five muscle strength exercises in this study, three exercises, i.e., Lunge, Single Leg Extension, and Rowing Squat, seem to be related to the motions of dorsiflexion and plantar flexion, whereas two exercises, i.e., Sideways Leg Lift and Single Leg Twist, seem to be related to eversion, but these motions seem to be relatively insufficient. Therefore, if programs to reinforce the motions of eversion, as well as those of dorsiflexion and plantar flexion, could be added in the next revisions of Nintendo Wii Fit Plus, it could achieve greater effects.

The balance training group showed a significant increase in the muscle strength of inversion at the angular velocities of $60^{\circ}$ and $120^{\circ}$ after the exercise. Hess and Woollacott ${ }^{29}$ ) reported that high-strength muscle strengthening training improved the balance of old people who had lost their sense of balance. This indicates that muscle strength training and balance training can influence each other. Therefore, it seems that the balance training games of Nintendo Wii Fit Plus strengthened the inversion muscles by promoting movement in the medial-lateral direction, as with the case of eversion in this study. The strengthening training group showed no significant difference in the muscle strength of inversion at the angular velocities of $60^{\circ}$ and $120^{\circ}$ after the exercise. This suggests the Nintendo Wii Fit Plus training in this study has insufficient intervention effects on inversion and eversion. Considering the results of this study, physical therapy approaches, such as Therabands and resistance training, will be necessary to strengthen the muscles of eversion and inversion in subjects with FAI. Even though the strengthening of eversion and inversion muscles was insufficient in this study, the strength of these muscles is very important for gait. For example, eversion must occur in the subtalar joint during the first $30-35 \%$ of the gait cycle, and inversion must occur in the subtalar joint for $15-20 \%$ after the first $35 \%$ of the gait cycle to allow for natural gait. Furthermore, the peroneus longus and brevis muscles are often used for intervention in the inversion ankle sprain, because the eversion muscles of the foot can give stability to the lateral surface of the ankle. However, these lateral muscles need much attention because they are very weak for unexpected inversion, even though they are at effective positions to resist inversion ${ }^{30,31)}$. Therefore, further studies on eversion and inversion are required to improve ankle instability.

This study has a few limitations. The natural ankle movement must occur at the oblique axis, rather than separately in plantar flexion, dorsiflexion, eversion, and inversion, and the terms pronation and supination are required for more accurate measurements. However, the measurements of muscle strength in this study were insufficient because they were made on the sagittal and horizontal planes. Future studies could present better results if they make improvements in this regard. In conclusion, Nintendo Wii Fit Plus training increased the muscle strength of plantar flexion and dorsi- flexion in the strengthening training group, and the muscle strength of plantar flexion, dorsiflexion, eversion, and inversion in the balance training group. Thus, the balance training group showed better results than the strengthening training group. Consequently, it is recommended to add the balance training of Nintendo Wii Fit Plus to conventional exercise programs to improve ankle muscle strength at a low cost.

\section{ACKNOWLEDGEMENT}

This study was supported by research funds from Gwangju University in 2015.

\section{REFERENCES}

1) Bridgman SA, Clement D, Downing A, et al.: Population based epidemiology of ankle sprains attending accident and emergency units in the West Midlands of England, and a survey of UK practice for severe ankle sprains. Emerg Med J, 2003, 20: 508-510. [Medline] [CrossRef]

2) Pires R, Pereira A, Abreu-E-Silva G, et al.: Ottawa ankle rules and subjective surgeon perception to evaluate radiograph necessity following foot and ankle sprain. Ann Med Health Sci Res, 2014, 4: 432-435. [Medline] [CrossRef]

3) Bendahou M, Khiami F, Saïdi K, et al.: Compression stockings in ankle sprain: a multicenter randomized study. Am J Emerg Med, 2014, 32: 10051010. [Medline] [CrossRef]

4) Freeman MA: Instability of the foot after injuries to the lateral ligament of the ankle. J Bone Joint Surg Br, 1965, 47: 669-677. [Medline]

5) Kim KJ, Kim YE, Jun HJ, et al.: Which treatment is more effective for functional ankle instability: strengthening or combined muscle strengthening and proprioceptive exercises? J Phys Ther Sci, 2014, 26: 385-388. [Medline] [CrossRef]

6) Abdel-aziem AA, Draz AH: Chronic ankle instability alters eccentric eversion/inversion and dorsiflexion/plantarflexion ratio. J Back Musculoskeletal Rehabil, 2014, 27: 47-53. [Medline]

7) Fu FL, Su RC, Yu SC: EGameFlow: a scale to measure learners' enjoyment of e-learning games. Comput Educ, 2009, 52: 101-112. [CrossRef]

8) Graves L, Stratton G, Ridgers ND, et al.: Energy expenditure in adolescents playing new generation computer games. Br J Sports Med, 2008, 42: 592-594. [Medline]

9) Dondi C, Moretti M: A methodological proposal for learning games selection and quality assessment. Br J Educ Technol, 2007, 38: 502-512. [CrossRef]

10) Vernadakis N, Gioftsidou A, Antoniou P, et al.: The impact of Nintendo Wii to physical education students' balance compared to the traditional approaches. Comput Educ, 2012, 59: 196-205. [CrossRef]

11) Papastergiou M: Exploring the potential of computer and video games for health and physical education: a literature review. Comput Educ, 2009, 53: 603-622. [CrossRef]

12) Plow M, Finlayson M: Potential benefits of nintendo wii fit among people with multiple sclerosis: a longitudinal pilot study. Int J MS Care, 2011, 13: 21-30. [Medline] [CrossRef]

13) Yang YR, Tsai MP, Chuang TY, et al.: Virtual reality-based training improves community ambulation in individuals with stroke: a randomized controlled trial. Gait Posture, 2008, 28: 201-206. [Medline] [CrossRef]

14) Kizony R, Raz L, Katz N, et al.: Video-capture virtual reality system for patients with paraplegic spinal cord injury. J Rehabil Res Dev, 2005, 42: 595-608. [Medline] [CrossRef]

15) Suárez H, Suárez A, Lavinsky L: Postural adaptation in elderly patients with instability and risk of falling after balance training using a virtualreality system. Int Tinnitus J, 2006, 12: 41-44. [Medline]

16) Kim KJ: Impact of combined muscle strength and proprioceptive exercises on functional ankle instability. J Int Acad Phys Ther Res, 2013, 4: 600-604. [CrossRef]

17) Michalski A, Glazebrook CM, Martin AJ, et al.: Assessment of the postural control strategies used to play two Wii Fit ${ }^{\mathrm{TM}}$ videogames. Gait Posture, 2012, 36: 449-453. [Medline] [CrossRef]

18) Elion O, Bahat Y, Sela I, et al.: Postural adjustments as an acquired motor skill: Delayed gains and robust retention after a single training session within a virtual environment. Virtual Rehabilitation, 2008: IEEE 2008:50-53. 
19) Van Ooteghem K, Frank JS, Allard F, et al.: Compensatory postural adaptations during continuous, variable amplitude perturbations reveal generalized rather than sequence-specific learning. Exp Brain Res, 2008, 187: 603-611. [Medline] [CrossRef]

20) Punt IM, Ziltener JL, Laidet M, et al.: Gait and physical impairments in patients with acute ankle sprains who did not receive physical therapy. PM R, 2015, 7: 34-41. [Medline] [CrossRef]

21) Guillebastre B, Calmels P, Rougier P: Effects of muscular deficiency on postural and gait capacities in patients with Charcot-Marie-Tooth disease J Rehabil Med, 2013, 45: 314-317. [Medline] [CrossRef]

22) Ng SS, Hui-Chan CW: Contribution of ankle dorsiflexor strength to walking endurance in people with spastic hemiplegia after stroke. Arch Phys Med Rehabil, 2012, 93: 1046-1051. [Medline] [CrossRef]

23) Fong DT, Chan YY, Mok KM, et al.: Understanding acute ankle ligamentous sprain injury in sports. BMC Sports Science. Med Rehabil, 2009, 1: 14.

24) Hertel J: Functional instability following lateral ankle sprain. Sports Med, 2000, 29: 361-371. [Medline] [CrossRef]

25) Crosbie J, Green T, Refshauge K: Effects of reduced ankle dorsiflexion following lateral ligament sprain on temporal and spatial gait parameters. Gait Posture, 1999, 9: 167-172. [Medline] [CrossRef]

26) Bakker JP, De Groot IJ, Beelen A, et al.: Predictive factors of cessation of ambulation in patients with Duchenne muscular dystrophy. Am J Phys Med Rehabil, 2002, 81: 906-912. [Medline] [CrossRef]

27) Son SM, Kang KW, Lee NK, et al.: Influence of isokinetic strength training of unilateral ankle on ipsilateral one-legged standing balance of adults. J Phys Ther Sci, 2013, 25: 1313-1315. [Medline] [CrossRef]

28) Pessoa TM, Coutinho DS, Pereira VM, et al.: The Nintendo Wii as a too for neurocognitive rehabilitation, training and health promotion. Comput Human Behav, 2014, 31: 384-392. [CrossRef]

29) Hess JA, Woollacott M: Effect of high-intensity strength-training on functional measures of balance ability in balance-impaired older adults. J Manipulative Physiol Ther, 2005, 28: 582-590. [Medline] [CrossRef]

30) Konradsen L: Sensori-motor control of the uninjured and injured human ankle. J Electromyogr Kinesiol, 2002, 12: 199-203. [Medline] [CrossRef]

31) Neumann DA: Kinesiology of the musculoskeletal system: foundations for rehabilitation. 2nd ed. St. Louis: Elsevier Health Sciences, 2010, pp 591-688. 